\title{
A steady state model for anaerobic digestion of sewage sludges
}

\author{
SW Sötemann, NE Ristow, MC Wentzel and GA Ekama* \\ Water Research Group, Department of Civil Engineering, University of Cape Town, Rondebosch 7701, Cape Town, South Africa
}

\begin{abstract}
A steady state model for anaerobic digestion of sewage sludge is developed that comprises three sequential parts - a kinetic part from which the \% COD removal and methane production are determined for a given retention time; a stoichiometry part from which the gas composition (or partial pressure of $\mathrm{CO}_{2}$ ), ammonia released and alkalinity generated are calculated from the \% COD removal; and a carbonate system weak acid/base chemistry part from which the digester $\mathrm{pH}$ is calculated from the partial pressure of $\mathrm{CO}_{2}$ and alkalinity generated. From the stoichiometry and weak acid base chemistry parts of the model, for a given \% COD removal, the digester gas composition, ammonia released, alkalinity generated and digester $\mathrm{pH}$ are completely defined by the influent sludge composition, i.e. $\mathrm{X}, \mathrm{Y}, \mathrm{Z}$ and $\mathrm{A}$ in $\mathrm{C}_{\mathrm{X}} \mathrm{H}_{\mathrm{Y}} \mathrm{O}_{\mathrm{Z}} \mathrm{N}_{\mathrm{A}}$ of the hydrolysable organics; volatile fatty acid (VFA) concentration; and $\mathrm{pH}$. For the kinetic part of the model, four hydrolysis kinetic equations were calibrated against 7 to $60 \mathrm{~d}$ retention time anaerobic digesters treating two different sewage sludge types, viz. first order; first order specific; Monod; and saturation. Once calibrated against the two sludge type data sets and taking into account experimental error in effluent COD concentration and gas production (i.e. COD mass balance error), each of the four hydrolysis kinetic equations predicted the \% COD removal versus retention time equally well, and predicted COD removal and methane production compared well with measured data. For the different sewage sludge types, viz. a primary and humus sludge mixture from a trickling filter plant, and a "pure" primary sludge, different kinetic rate constants were obtained indicating that the "pure" primary sludge hydrolysed faster and had a lower unbiodegradable particulate COD fraction $\left(\mathrm{f}_{\mathrm{PS} \text { up }}=0.33\right)$ than the primary and humus sludge mixture (0.36). With the \%COD removal known from the hydrolysis part of the model, and again taking experimental error into account (i.e. $\mathrm{C}$ and $\mathrm{N}$ mass balances error), the stoichiometry and weak acid base chemistry parts of the model predicted the gas composition, effluent free and saline ammonia (FSA) concentration, alkalinity generated and digester $\mathrm{pH}$ well for a primary and humus sludge composition of $\mathrm{C}_{3,5} \mathrm{H}_{7} \mathrm{O}_{2} \mathrm{~N}_{0196}$. From independent measurement of primary sludge CHON composition, this model estimated composition is within $96 \%, 100 \%, 95 \%$ and $99 \%$ of the average measured composition of $\mathrm{C}_{3.65} \mathrm{H}_{7} \mathrm{O}_{197} \mathrm{~N}_{0.190}$ lending strong support to the developed steady state model.
\end{abstract}

Keywords: Anaerobic digestion, steady state model, sewage sludge, hydrolysis kinetics, biodegradability

\section{Introduction}

Sötemann et al. (2005a) developed an integrated two-phase (aqueous-gas) mixed weak acid base chemical, physical and biological processes kinetic model for anaerobic digestion (AD) of sewage sludge. The COD, $\mathrm{C}$ and $\mathrm{N}$ mass balances and continuity basis of this model fixes quantitatively, via the interrelated chemical, physical and biological processes, the relationship between all the compounds of the system. Thus for a given sewage sludge COD removal the digester outputs (i.e. effluent COD, TKN, FSA, SCFA, $\mathrm{H}_{2} \mathrm{CO}_{3} * \mathrm{Alk}, \mathrm{pH}$, gaseous $\mathrm{CO}_{2}$ and $\mathrm{CH}_{4}$ production and partial pressures) are governed completely by the input sludge solids (and dissolved) constituents. In this model, the sewage sludge feed is characterised in terms of total COD, its particulate unbiodegradable COD fraction ( $\left.\mathrm{f}_{\mathrm{PS} \text { 'up }}\right)$, the short chain fatty acid (SCFA) COD and the CHON content, i.e. $\mathrm{X}, \mathrm{Y}, \mathrm{Z}$ and $\mathrm{A}$ in $\mathrm{C}_{\mathrm{X}} \mathrm{H}_{\mathrm{Y}} \mathrm{O}_{\mathrm{Z}} \mathrm{N}_{\mathrm{A}}$ of the particulate organics. This approach characterises the sludge in terms of measurable parameters in conformity with the COD, $\mathrm{C}$ and $\mathrm{N}$ mass balances approach. With this approach, the interactions between the biological processes and weak acid/base chemistry could be correctly predicted for stable steady state operation of anaerobic digesters. While not validated for dynamic flow and load

\footnotetext{
* To whom all correspondence should be addressed.

菌 +27 21650 2588/0/4; fax: +27 216897471 ;

e-mail: ekama@ebe.uct.ac.za

Received 6 December 2004; accepted in revised form 8 August 2005.
}

conditions, the model has the capability of being applied to such conditions. In this paper this complex dynamic simulation model is simplified to a steady state one for integration into a steady state mass balance model of the whole wastewater treatment plant (Sötemann et al., 2005b).

Steady state models are based on the slowest process kinetic rate that governs the overall behaviour of the system and relates this process rate to the system design and operating parameters. Therefore, steady state models allow the system design and operating parameters, such as reactor volume and recycle ratios, to be estimated reasonably simply and quickly from system performance criteria specified for the design, such as effluent quality. Once approximate design and operating parameters are known, these can serve as input to the more complex simulation models to investigate dynamic behaviour of the system and refine the design and operating parameters. A steady state AD model is therefore useful to:

- estimate retention time, reactor volume, gas production and composition for a required system performance like COD (or VSS) removal,

- investigate the sensitivity of the system performance to the design and operation parameters,

- provide a basis for cross-checking simulation model results, and

- estimate product stream concentrations for design of down(or up-) stream unit operations of the wastewater treatment plant.

Anaerobic digestion of organics require a consortium of four organism groups (Mosey, 1983; Massé and Droste, 2000; 
Batstone et al., 2002; Sötemann et al., 2005a) viz.:

(i) acidogens, which convert complex organics to SCFA acetic and propionic ( $\mathrm{HAc}, \mathrm{HPr})$, carbon dioxide $\left(\mathrm{CO}_{2}\right)$ and hydrogen $\left(\mathrm{H}_{2}\right)$,

(ii) acetogens, which convert $\mathrm{HPr}$ to $\mathrm{HAc}$ and $\mathrm{H}_{2}$,

(iii)acetoclastic methanogens, which convert $\mathrm{HAc}$ to $\mathrm{CO}_{2}$ and methane $\left(\mathrm{CH}_{4}\right)$ and

(iv) hydrogenotrophic methanogens, which convert $\mathrm{H}_{2}$ and $\mathrm{CO}_{2}$ to $\mathrm{CH}_{4}$ and water.

The two methanogenic groups are very sensitive to $\mathrm{pH}$ and so the acetogens and acetoclastic methanogens must utilise the HAc and HPr respectively as soon as they are produced to maintain a near neutral $\mathrm{pH}$ for optimal operation. Because the hydrolysis/acidogenesis process mediated by the acidogens ((i) above), is the slowest process in the system, high SCFA concentrations and therefore low $\mathrm{pH}$, arise only under unstable and digester upset operating conditions caused by a shock load in organics, a rapid decrease in temperature or a methanogen inhibitor in the influent. A steady state model, therefore, need only consider the kinetics of this process (Vavilin et al., 2001). The processes following hydrolysis/acidogenesis, being much more rapid (usually), can be accepted to reach completion. This implies that in stable AD systems the intermediate products of the processes following after hydrolysis/acidogenesis such as SCFAs and $\mathrm{H}_{2}$, do not build up in the system and their concentrations are sufficiently low to be considered negligible. Consequently, in the steady state AD model, the products of hydrolysis/acidogenesis can be dealt with stoichiometrically and converted to digester end products. In effect, it can be assumed that the hydrolysis/ acidogenesis process generates directly the digester end-products biomass, $\mathrm{CH}_{4}, \mathrm{CO}_{2}$ and water. Thus the steady state anaerobic digester model developed below considers three aspects:

(1) the kinetics of the hydrolysis/acidogenesis process,

(2) stoichiometric conversion of the products from (1) to digester end-products and

(3) the effect of the end products on the digester $\mathrm{pH}$ (weak acid/ base chemistry).

\section{Hydrolysis/acidogenesis kinetics}

\section{Hydrolysis rate equations}

Since the hydrolysis/acidogenesis process is the slowest one in the sewage sludge anaerobic digester and does not reach completion within the normal range of the principal digester design parameter of hydraulic retention time, a kinetic expression describing this process rate is required for the steady state model. Sötemann et al. (2005a) considered four kinetic equations for this process, viz.:

- first order with respect to the residual biodegradable particulate organic (COD) concentration $\mathrm{S}_{\mathrm{bp}}$,

- first order with respect to $S_{b p}$ and the acidogen biomass concentration $\left(\mathrm{Z}_{\mathrm{AD}}\right)$ which mediates this process,

- Monod kinetics and

- saturation (or Contois) kinetics (see Eqs 1 to 4 in Table 1).

All these equations have been used to model various biological processes for many years; the first to describe the hydrolysis/acidogenesis of sewage sludge solids in AD (e.g. Henze and Harremoës, 1983, Bryers, 1985, Vavilin et al., 2001), the second for modelling the conversion of readily biodegradable organics to short chain fatty acids in the anaerobic reactor of biological P removal systems (e.g. Wentzel et al., 1985), and the last two for the utilisation of soluble readily and particulate slowly biodegradable organics respectively in activated sludge models (Dold et al., 1980; Henze et al., 1987) and hydrolysis of complex organics in AD (e.g. McCarty, 1974 and Vavilin et al., 2001). Sötemann et al. (2005a) were unable to determine which equation was superior for modelling hydrolysis/acidogenesis process in $\mathrm{AD}$ because for the experimental data evaluated, the unbiodegradable particulate COD fraction $\left(f_{\mathrm{PS} \text { 'up }}\right)$ of the sewage sludge (primary+humus) organics was not sufficiently well known - by changing $\mathrm{f}_{\mathrm{PS} \text { up }}$ in a fairly narrow range from 0.32 to 0.36 , each of the equations gave a better correlation coefficient than the other equations at different specific $\mathrm{f}_{\mathrm{PS} \text { 'up }}$ values. They accepted the saturation kinetics for the integrated model(UCTADM1) because this equation gave a similar $\mathrm{f}_{\text {PS'up }}$ value (0.36) to O'Rouke (1967) (0.34) working with AD of "pure" primary sludge (no trickling filter humus or waste activated sludge) and has been successfully used to model hydrolysis/utilisation of the same particulate biodegradable organics in activated sludge kinetic models. In their comparison of first order and saturation (Contois) kinetics for modelling anaerobic hydrolysis, Vavilin et al. (2001) state that the latter is preferable from a modelling perspective (and is another reason these kinetics were included in the dynamic $\mathrm{AD}$ model of Sötemann et al., 2005a), but the uncertainty that the unknown unbiodegradable COD fraction of the influent organics casts over hydrolysis kinetics selection is not mentioned. In their evaluation of the four hydrolysis/acidogenesis equations, Sötemann et al. (2005a) included the effect of the acidogen $\left(Z_{A D}\right)$ and acetoclastic methanogen $\left(\mathrm{Z}_{\mathrm{AM}}\right)$ biomass formation, because these two organism groups have the highest yield coefficients and so contribute significantly to the effluent organics (COD) concentration and decrease the gas production.

In steady state models, detail is not required - in fact, it is undesirable. From the simulation model, sufficient accuracy for a steady state model is obtained by selecting any of the four hydrolysis/acidogenesis equations and increasing the acidogen biomass yield to include the acetoclastic methanogens. The acidogens have the highest yield coefficient $\left(\mathrm{Y}_{\mathrm{AC}}=0.089 \mathrm{gCOD}\right.$ biomass/gCOD substrate hydrolysed) and make up more than $77 \%$ of the total biomass formed. Increasing $\mathrm{Y}_{\mathrm{AD}}$ from 0.089 to 0.113 very closely takes into account the biomass formation of the other organism groups (see Fig. 4 of Sötemann et al., 2005a). A consequence of accepting this approach is that in kinetic rate formulations that include the acidogen biomass concentration (first order specific, Monod and saturation), the specific rate constants in the steady state model here will be lower compared with the corresponding values in the dynamic model of Sötemann et al. (2005a) but the predicted performances (e.g. \%COD removal) will be the same.

The steady state model will be derived using the COD to quantify the organics and biomass concentrations and the Monod equation for the hydrolysis/acidogenesis rate. However, the model equations for all four hydrolysis kinetics rate expressions have been derived and are summarised in Table 1.

\section{Steady state model development - hydrolysis kinetics}

Consider a flow through digester of volume $\mathrm{V}$ and influent flow $\mathrm{Q}$ giving a hydraulic retention time or sludge age of $\mathrm{R}=\mathrm{V} / \mathrm{Q}$ days (Fig. 1).

Defining the unbiodegradable fraction of the influent total particulate sewage sludge $\operatorname{COD}\left(\mathrm{S}_{\mathrm{ti}}\right)$ as $\mathrm{f}_{\mathrm{PS} \text { 'u }}$, then the particulate biodegradable $\left(\mathrm{S}_{\mathrm{bpi}}\right)$ and unbiodegradable $\left(\mathrm{S}_{\mathrm{upi}}\right)$ COD concentrations in the influent are (see Fig. 2): 


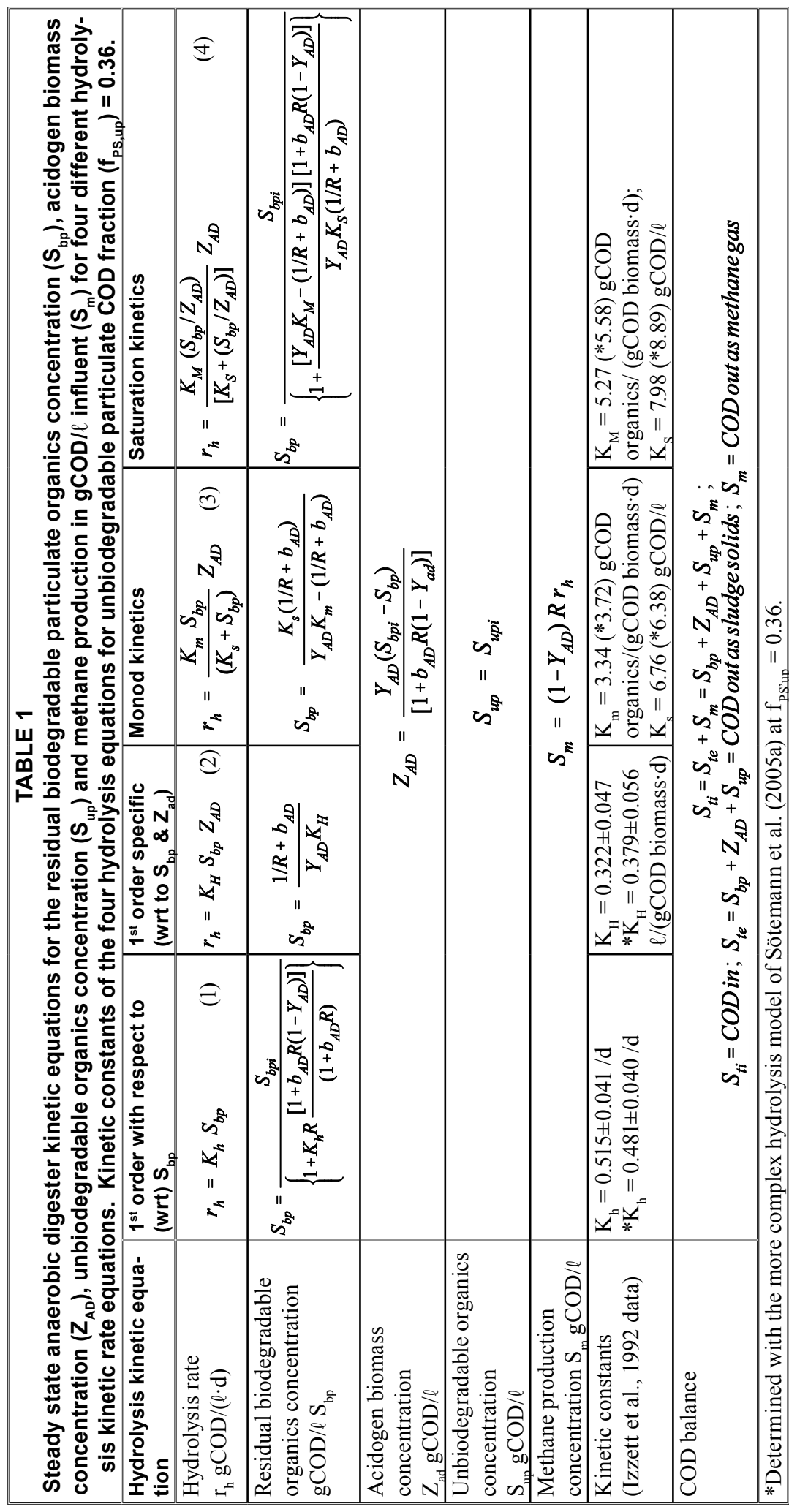

$$
\begin{aligned}
& S_{b p i}=\left(1-f_{P S^{\prime} u p}\right) S_{t i}-S_{b s a i} \\
& S_{u p i}=f_{P S^{\prime} u p} S_{t i}
\end{aligned}
$$

where:

$$
\begin{aligned}
\mathrm{S}_{\text {bsai }}= & \text { Influent volatile fatty acid } \\
& (\text { VFA) concentration }(\operatorname{mgCOD} / \ell)
\end{aligned}
$$

Sewage sludge comprises two additional dissolved COD fractions, i.e. the unbiodegradable soluble $\operatorname{COD}\left(\mathrm{S}_{\text {usi }}\right)$ and the fermentable (non-VFA) readily biodegradable soluble $\mathrm{COD}\left(\mathrm{S}_{\mathrm{bsfi}}\right)$ (Fig. 2). The $\mathrm{S}_{\text {usi }}$ is very low in relation to the $\mathrm{S}_{\text {upi }}$ and so can be assumed zero for the purposes of this steady state model. The $\mathrm{S}_{\mathrm{bsfi}}$ goes through the same hydrolysis/acidogenesis processes as the particulate biodegradable $\operatorname{COD}\left(\mathrm{S}_{\mathrm{bpi}}\right)$ and so is included with the $\mathrm{S}_{\mathrm{bpi}}$. Because the steady state model is based on the hydrolysis process as stated in Eq. 5, the $\mathrm{S}_{\mathrm{bsai}}$ is not included with the COD passing through this process. However, the $\mathrm{S}_{\text {bsai }}$ does generate methane and $\mathrm{CO}_{2}$ (but negligible sludge mass) mediated by the two methanogenic species. Hence $\mathrm{S}_{\text {bsai }}$ can be excluded in the hydrolysis part of the model but needs to be included in the stoichiometry part of the model due to its effect on gas composition and digester $\mathrm{pH}$. Hence $\mathrm{S}_{\mathrm{ti}}$ is given by $\mathrm{S}_{\text {upi }}+\mathrm{S}_{\text {bpi }}+\mathrm{S}_{\text {bsai }}$ (Fig. 2).

The net acidogen growth rate from the hydrolysis/acidogenesis and endogenous processes is given by:

$\frac{d Z_{A D}}{d t}=Y_{A D} r_{h}-b_{A D} Z_{A D}$

where:

$\mathrm{r}_{\mathrm{h}}=$ volumetric hydrolysis/acidogenesis rate in $\mathrm{gCOD} /(\ell \cdot \mathrm{d})($ Eqs. 1 to 4 in Table 1)

$\mathrm{Y}_{\mathrm{AD}}=$ pseudo acidogen yield coefficient (gCOD biomass/gCOD organics hydrolysed)

$\mathrm{b}_{\mathrm{AD}}=$ acidogen endogenous respiration rate $(/ d)$.

The steady state model is derived by applying the general mass balance equation (Eq. 7) over the system (Fig. 1) to the four system variable compound concentrations (all gCOD/ $/$ ), i.e. $\mathrm{S}_{\mathrm{bp}}, \mathrm{S}_{\mathrm{up}}, \mathrm{Z}_{\mathrm{AD}}$ and methane

Figure 1

Schematic diagram of the flow through anaerobic digester of retention time $R=V / Q$ showing symbols used in the steady state $A D$ model.

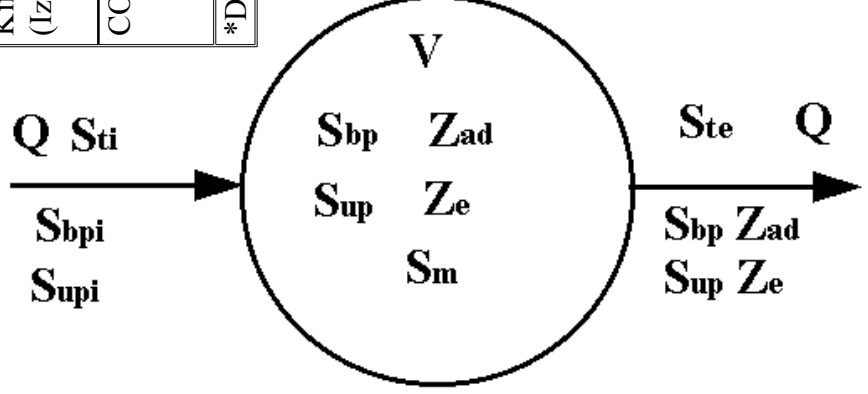




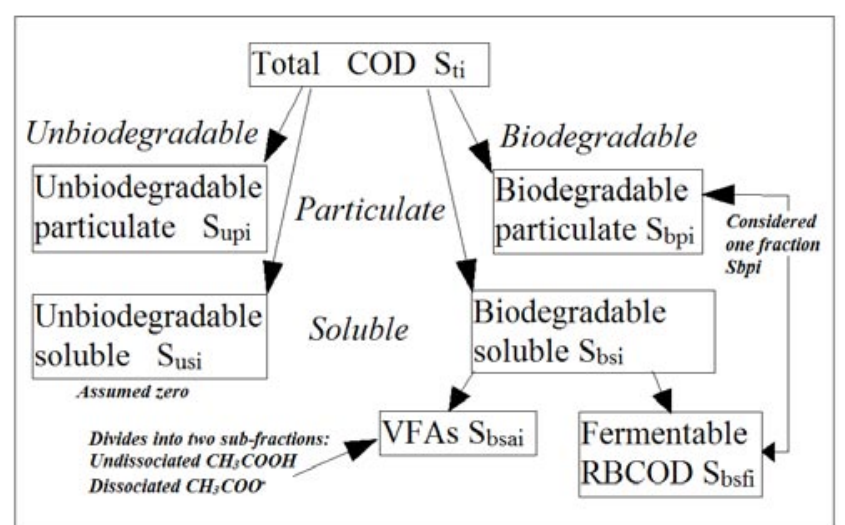

Figure 2

Influent primary sludge COD fractionation for the steady state anaerobic digestion model

$\left(\mathrm{S}_{\mathrm{m}}\right)$ concentrations. For the flow through system, the effluent compound concentrations are equal to the reactor concentrations. For example, the mass balance for $\mathrm{S}_{\mathrm{bp}}$ over a time interval $\mathrm{dt}$ is:

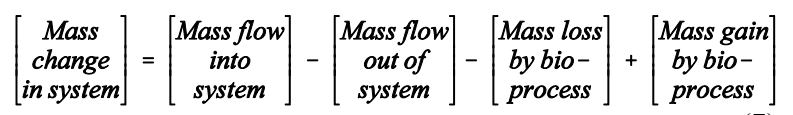

$$
d S_{b p} V=+Q S_{b p i} d t-Q S_{b p} d t-r_{h} V d t+b_{A D} Z_{A D} V d t
$$

In Eq. 8, the first and second terms on the right hand side are the biodegradable organics flowing in and out of the digester, and the third and fourth terms the decrease in biodegradable organics due to hydrolysis and the increase from the biodegradable part of the acidogen biomass that dies. Dividing Eq. 8 through by Vdt yields:

$$
\frac{d S_{b p}}{d t}=+\frac{S_{b p i}-S_{b p}}{R}-r_{h}+b_{A D} Z_{A D} \quad \mathrm{gCOD} /(\ell . \mathrm{d})
$$

Similarly the mass balance on acidogen biomass concentration $\left(Z_{\mathrm{AD}}\right)$ yields:

$$
d Z_{A D} V=+0-Q Z_{A D} d t+Y_{A D} r_{h} V d t-b_{A D} Z_{A D} V d t
$$

Again dividing through by Vdt yields:

$$
\frac{d Z_{A D}}{d t}=-\frac{Z_{A D}}{R}+Y_{A D} r_{h}-b_{A D} Z_{A D}
$$

At steady state the transient $\mathrm{dZ}_{\mathrm{AD}} / \mathrm{dt}$ in Eq. $10=0$ and solving for the hydrolysis rate $\mathrm{r}_{\mathrm{h}}$ yields:

$$
r_{h}=\frac{Z_{A D}}{Y_{A D}}\left(\frac{1}{R}+b_{A D}\right) \quad \mathrm{gCOD} /(\text { l.d })
$$

Setting Eq. $9=0$ for steady state and solving for $\mathrm{r}_{\mathrm{h}}$ yields:

$$
r_{h}=\frac{S_{b p i}-S_{b p}}{R}+b_{A D} Z_{A D}
$$

Then substituting Eq. 11 for $\mathrm{r}_{\mathrm{h}}$ into Eq. 12 and solving for $\mathrm{Z}_{\mathrm{AD}}$ yields:

$$
\begin{aligned}
& Z_{A D}=\frac{Y_{A D}\left(S_{b p i}-S_{b p}\right)}{\left[1+b_{A D} R\left(1-Y_{A D}\right)\right]}=\left(S_{b p i}-S_{b p}\right) E: \\
& =\Delta S_{b p} E \quad \mathrm{gCOD} / \ell
\end{aligned}
$$

Equation 13 seems to indicate that the acidogen biomass concen- tration $\left(\mathrm{Z}_{\mathrm{AD}}\right)$ is independent of the hydrolysis kinetic rate (and hence its formulation) because $r_{h}$ does not appear in it. However, it is implicitly dependent on $r_{h}$ because $S_{b p}$ appears in the equation and $\mathrm{S}_{\mathrm{bp}}$ is dependent on the hydrolysis kinetic rate. Equation 13 does show that once $S_{b p}$ is known, then $Z_{A D}$ can be calculated for any hydrolysis rate equation.

Substituting the Monod equation (Eq. 3 in Table 1) for $r_{h}$ into Eq. 11 and solving for $\mathrm{S}_{\mathrm{bp}}$ yields:

$$
S_{b p}=\frac{K_{s}\left(1 / R+b_{A D}\right)}{Y_{A D} K_{m}-\left(1 / R+b_{A D}\right)} \mathrm{gCOD} / \ell
$$

Ignoring as negligible the formation of unbiodegradable organics from the acidogens that die (i.e. endogenous residue is zero), the total unbiodegradable organics concentration in the effluent $\left(\mathrm{S}_{\text {up }}\right)$ is equal to the influent, i.e.

$$
S_{u p}=S_{u p i} \quad \mathrm{gCOD} / \ell
$$

The methane production in COD units is directly related to the rate of hydrolysis of biodegradable organics. If the methane concentration in the effluent in COD units is $\mathrm{S}_{\mathrm{m}}$, a mass balance on $\mathrm{S}_{\mathrm{m}}$ yields:

$$
d S_{m} V=0-Q S_{m} d t+\left(1-Y_{A D}\right) r_{h} V d t
$$

where:

$$
\begin{aligned}
& \mathrm{S}_{\mathrm{m}}= \text { methane concentration in the effluent in } \mathrm{gCOD} / \ell \\
& \text { (if it were dissolved) }
\end{aligned}
$$

Dividing Eq. 16 through by $\mathrm{Vdt}$ and setting $\mathrm{dS}_{\mathrm{m}} / \mathrm{dt}=0$ and solving for $\mathrm{S}_{\mathrm{m}}$ yields:

$$
S_{m}=\left(1-Y_{A D}\right) R r_{h} \quad \mathrm{gCOD} / \ell
$$

Because methane has a COD $64 \mathrm{gCOD} / \mathrm{mol}$ and a gas volume at ambient temperature $20^{\circ} \mathrm{C}$ of $22.4(293 / 273)=24.0 \mathrm{l} / \mathrm{mole}$, the methane gas production $\mathrm{Q}_{\mathrm{m}}$ is:

$$
Q_{m}=\left(1-Y_{A D}\right) R r_{h} 24.0 / 64
$$

( $\ell$ methane/d) /( $($ influent flow/d)

The partial pressure of $\mathrm{CO}_{2}$ in the gas $\left(\mathrm{p}_{\mathrm{CO} 2}\right)$ and the $\mathrm{CO}_{2}$ composition of the gas are numerically equal. Hence, if the partial pressure of $\mathrm{CO}_{2}$ or the $\mathrm{CO}_{2}$ gas composition are known (in atmospheres, or volume or mole fractions), then the total gas production at $20^{\circ} \mathrm{C}\left(\mathrm{Q}_{\mathrm{gas}}\right)$ is:

$$
Q_{\text {gas }}=\frac{Q_{m}}{\left(1-p_{C O 2}\right)}=\frac{\left(1-Y_{A D}\right) R r_{h} 24.0}{\left(1-p_{C O 2}\right) 64}
$$

$(\ell$ gas $/ \mathrm{d}) /(\ell$ influent flow $/ \mathrm{d})$

A COD mass balance over the digester system (Fig. 1) yields:

$$
S_{t i}=S_{t e}+S_{m}=S_{b p}+Z_{A D}+S_{u p}+S_{m}
$$

Equation 20 shows that COD exits the digester only as sludge mass in the effluent $\left(\mathrm{S}_{\mathrm{te}}\right)$ and as methane gas $\left(\mathrm{S}_{\mathrm{m}}\right)$. Substituting Eq. 13 with $\mathrm{S}_{\mathrm{bp}}$ as its subject for $\mathrm{S}_{\mathrm{bp}}$, Eq. 15 for $\mathrm{S}_{\mathrm{up}}$, Eq. 17 for $\mathrm{S}_{\mathrm{m}}$ and Eq. 3 for $\mathrm{r}_{\mathrm{h}}$ into Eq. 20 yields:

$$
\begin{aligned}
& S_{t i}=S_{b p i}-\frac{Z_{A D}}{V}\left[1+b_{A D} R\left(1-Y_{A D}\right)\right]+Z_{A D} \\
& +S_{u p i}+\left(1-Y_{A D}\right) R \frac{K_{m} S_{b p}}{K_{s}+S_{b p}} Z_{A D}
\end{aligned}
$$


which on simplifying gives Eq. 14 for $\mathrm{S}_{\mathrm{bp}}$, and therefore proves the input and output COD masses balance exactly.

The total $\left(\mathrm{S}_{\mathrm{tr}}\right)$ and biodegradable $\left(\mathrm{S}_{\mathrm{bpr}}\right)$ COD removals and methane production $\left(\mathrm{S}_{\mathrm{m}}\right)$ are given by:

$$
\begin{aligned}
& S_{t r}=S_{t i}-S_{t e}=S_{m} \\
& S_{b p r}=S_{b p i}-S_{b p}
\end{aligned}
$$

The equations for the biodegradable organics $\left(\mathrm{S}_{\mathrm{bp}}\right)$, acidogen $\left(\mathrm{Z}_{\mathrm{AD}}\right)$, unbiodegradable $\left(\mathrm{S}_{\mathrm{up}}\right)$ and methane $\left(\mathrm{S}_{\mathrm{m}}\right)$ concentrations for all four hydrolysis rate formulations are given in Table 1.

\section{Calibration of hydrolysis kinetics}

The equations developed above were evaluated and calibrated against data from steady state anaerobic digesters.

\section{Calculating the effluent COD concentration $\left(S_{t e}\right)$}

From the steady state COD mass balance equation (Eq. 20), the effluent total particulate COD concentration, $\mathrm{S}_{\mathrm{te}}$ is given by:

$$
S_{t e}=S_{u p}+S_{b p}+Z_{A D} \mathrm{gCOD} / \ell
$$

Substituting Eq. 15 for $\mathrm{S}_{\text {up }}$, Eq. 6 for $\mathrm{S}_{\text {upi }}$ and Eq. 13 for $\mathrm{Z}_{\mathrm{AD}}$ in Eq. 23 yields:

$$
S_{t e}=f_{P S^{\prime} u p} S_{t i}+S_{b p}+\frac{Y_{A D}\left[\left(1-f_{P S^{\prime} u p}\right) S_{t i}-S_{b p}\right]}{\left[1+b_{A D} R\left(1-Y_{A D}\right)\right]} \mathrm{gCOD} / \ell
$$

Solving Eq. 24 for $\mathrm{S}_{\mathrm{bp}}$ yields:

$$
\begin{aligned}
& S_{b p}=\frac{S_{t i}\left[f_{P S^{\prime} u p}+E\left(1-f_{P S^{\prime} u p}\right)\right]-S_{t e}}{[E-1]} \mathrm{gCOD} / \ell \\
& \text { where } E=\frac{Y_{A D}}{1+b_{A D} R\left(1-Y_{A D}\right)} \text { (From Eq 13) }
\end{aligned}
$$

With $\mathrm{S}_{\mathrm{te}}$ and $\mathrm{S}_{\mathrm{ti}}$ known from measurement, Eq. 25 defines $\mathrm{S}_{\mathrm{bp}}$ in terms of the unbiodegradable fraction of the primary sludge $\left(\mathrm{f}_{\mathrm{PS} \text { 'up }}\right)$, the retention time of the digester $(\mathrm{R})$ and the acidogen constants $\left(\mathrm{Y}_{\mathrm{AD}}, \mathrm{b}_{\mathrm{AD}}\right)$. By estimating an unbiodegradable fraction of the primary sludge $\left(\mathrm{f}_{\mathrm{PS} \text { up }}\right)$ and selecting acidogen biomass constants (i.e. $\mathrm{Y}_{\mathrm{AD}}=0.113 \mathrm{gCOD}$ biomass/ gCOD organics, $\mathrm{b}_{\mathrm{AD}}$ $=0.041 / \mathrm{d}), \mathrm{S}_{\mathrm{bp}}$ can be calculated with Eq. 25 from experimental data. The yield coefficient of the acidogens $\left(\mathrm{Y}_{\mathrm{AD}}\right)$ has been increased from 0.089 to 0.113 to take account of the acetoclastic methanogen biomass that grows in the system. Because acidogenesis produces $61 \%$ acetic acid (and 39\% hydrogen), 61\% of the acetoclastic methanogen yield coefficient $\left(\mathrm{Y}_{\mathrm{AM}}=0.040\right)$ was added to $Y_{A D}$. This simplification is acceptable because the endogenous respiration rate is closely the same for these two organism groups $\left(b_{A D}=0.041 / d\right.$ and $\left.b_{A M}=0.037 / d\right)$. However, as noted above this simplification does influence the values of the constants in the hydrolysis rate equations. The hydrogenotrophic methanogen yield $\left(\mathrm{Y}_{\mathrm{HM}}\right)$ is low enough (0.01 gCODbiomass/gCOD $\mathrm{H}_{2}$ ) to be ignored.

\section{Estimating the unbiodegradable COD fraction of primary sludge}

For wastewater treatment plant design, the primary sludge (PS) unbiodegradable COD fraction $\left(\mathrm{f}_{\mathrm{PS} \text { up }}\right)$ is entirely dependent on the unbiodegradable particulate COD fractions $\left(f_{S^{\prime} \text { up }}\right)$ selected for the raw and settled wastewaters and the fraction of COD removed by primary sedimentation $\left(f_{p s r}\right)$. From a COD mass bal-

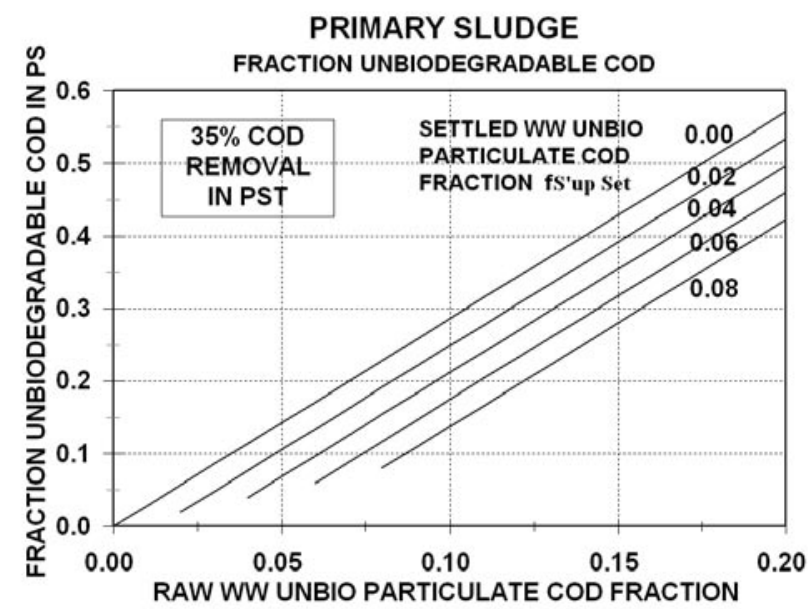

Figure 3

Fraction of unbiodegradable COD in primary sludge versus raw wastewater unbiodegradable particulate $C O D$ fraction for different settled wastewater unbiodegradable particulate COD fraction

ance around the primary settling tank (PST), the $\mathrm{f}_{\text {PS'up }}$ in terms of the raw and settled wastewater $\mathrm{f}_{\text {S up }}$ values and the PST $\mathrm{f}_{\mathrm{psr}}$ is:

$$
\begin{aligned}
& f_{P S^{\prime} u p}=f_{S^{\prime} \text { upSet }}+\frac{1}{f_{p s r}}\left(f_{S^{\prime} \text { upRaw }}-f_{S^{\prime}{ }_{u p S e t}}\right) \\
& \mathrm{f}_{\text {PS'up }}=\text { unbiodegradable COD fraction of primary } \\
& \text { sludge (PS) } \\
& \mathrm{f}_{\text {S'up Set }}=\text { Settled wastewater unbiodegradable particulate } \\
& \text { COD fraction } \\
& \mathrm{f}_{\text {Sup Raw }}=\text { Raw wastewater unbiodegradable particulate } \\
& \text { COD fraction } \\
& \mathrm{f}_{\mathrm{psr}}=\text { fraction of COD removed in the primary settling }
\end{aligned}
$$

Equation 26 has been simplified and is not strictly in conformity with a water flow balance over the PST. In Eq. 26, it has been assumed that the raw and settled wastewater flows entering and exiting the PST are equal. In practice, this is not true due to the low PST underflow, typically between 0.5 and $2 \%$ of average dry weather flow (ADWF). The error is very small on $\mathrm{f}_{\mathrm{PS} \text { up }}$, but large enough to cause an error of $\sim 1 \%$ on the COD mass balance around the whole WWTP. Mass balances are used wherever possible to verify the mathematical equations in models and errors $>1 \%$ are signals of possible errors in logic and formulae.

A graphical representation of Eq. 26 is given in Fig. 3. For the typical South African raw and settled municipal wastewaters, $\mathrm{f}_{\text {S'up }^{\prime}}$ fractions of 0.15 and 0.04 respectively (WRC, 1984) and $35 \%$ COD removal ( $f_{\text {psr }}=0.35$ ), the $f_{\text {PS'up }}$ is 0.36 . Literature on full-scale AD of primary sludge (PS) give maximum VS removals at long retention times at around 0.60 (Eckenfelder, 1980), suggesting an unbiodegradable fraction of around 0.35 . O'Rourke (1967) determined a $\mathrm{f}_{\text {PS'up }}$ of 0.36 in their investigation into AD of PS.

Incidently, Eq. 26 shows that the $f_{\text {s'up }}$ values selected for the raw and settled wastewaters must be consistent with observed PS characteristics; and the \% removal of unbiodegradable organics (COD) in PSTs is apparently much higher ( $83 \%$ for the selected $\mathrm{f}_{\text {S'up }}$ values above) than that of biodegradable organics $(38 \%)$. The latter is of significant economic benefit for the activated sludge system because a large mass of burdensome unbiodegradable organics from the influent do not accumulate in the reactor. In some wastewater treatment plant simulation models, equal proportions of biodegradable and unbiodegradable 
particulate organics are removed in the PST. This leads to settled wastewater and PS characteristics that deviate significantly from observed values, e.g. if equal proportions of the raw wastewater biodegradable and unbiodegradable particulate COD are

\begin{tabular}{|c|c|c|c|c|c|}
\hline \multicolumn{6}{|c|}{$\begin{array}{c}\text { TABLE } 2 \\
\text { Experimental data measured by Izzett et al. (1992) on } 14 \ell \\
\text { completely mixed mesophilic }\left(37^{\circ} \mathrm{C}\right) \text { anaerobic digesters at } 7 \text { to } \\
20 \mathrm{~d} \text { retention time fed a mixture of primary and humus (trickling filter) } \\
\text { sludge from the Potsdam wastewater treatment plant } \\
\text { (Milnerton, Cape, South Africa) }\end{array}$} \\
\hline Retention time (d) & 7 & 10 & 12 & 15 & 20 \\
\hline Influent flow $\ell / \mathrm{d}$ & 2.00 & 1.40 & 1.17 & 0.93 & 0.70 \\
\hline Influent $\mathrm{COD} \mathrm{gCOD} / \ell$ & 43.286 & 40.721 & 39.222 & 42.367 & 42.595 \\
\hline Influent VFA $\mathrm{mgCOD} / \ell$ & 1871 & 1961 & 2872 & 1824 & 2249 \\
\hline Influent TKN mgN/ $\ell$ & 1105 & 1100 & 1028 & 1075 & 1171 \\
\hline Influent FSA mgN/ $\ell$ & 196 & 203 & 235 & 221 & 244 \\
\hline Influent Alk mg/ $\ell$ as $\mathrm{CaCO}_{3}$ & 80 & 81 & 90 & 82 & 56 \\
\hline Influent $\mathrm{pH}$ & 5.34 & 5.34 & 5.20 & 5.42 & 5.28 \\
\hline Effluent COD gCOD $/ \ell$ & 23.637 & 20.521 & 18.678 & 19.969 & 19.005 \\
\hline Effluent VFA mgCOD/ $\ell$ & 50 & 28 & 28 & 27 & 23 \\
\hline Effluent TKN mgN/ $\ell$ & 1041 & 1039 & 992 & 976 & 1157 \\
\hline Effluent FSA mgN/ $\ell$ & 511 & 404 & 430 & 404 & 511 \\
\hline Effluent $\mathrm{Alk} \mathrm{mg} / \ell$ as $\mathrm{CaCO}_{3}$ & 1882 & 1951 & 2072 & 1994 & 2066 \\
\hline Gas composition $\% \mathrm{CH}_{4}$ & 63.2 & 62.1 & 63.3 & 63.6 & 63.3 \\
\hline COD removal & 19.649 & 20.200 & 20.544 & 22.398 & 23.590 \\
\hline Gas prod $\ell$ gas $/ \ell$ influent & 13.97 & 14.33 & 14.27 & 15.01 & 15.79 \\
\hline Gas Composition $\% \mathrm{CO}_{2}$ & 36.8 & 37.9 & 36.7 & 36.4 & 36.7 \\
\hline FSA released $\mathrm{mgN} / \ell$ & 315 & 201 & 195 & 183 & 267 \\
\hline Measured digester $\mathrm{pH}$ & 7.12 & 7.11 & 7.19 & 7.14 & 7.15 \\
\hline "Corrected" digester $\mathrm{pH}$ & 6.84 & 6.84 & 6.88 & 6.86 & 6.87 \\
\hline COD balance (\%) & 108.4 & 108.6 & 109.1 & 106.9 & 107.3 \\
\hline Nitrogen balance (\%) & 94.2 & 94.5 & 96.5 & 90.8 & 98.8 \\
\hline Carbon balance (\%)* & 99.0 & 100.0 & 99.5 & 101.3 & 101.4 \\
\hline
\end{tabular}

removed and the $\% \mathrm{COD}$ removal remains at $35 \%$, then the settled wastewater $\mathrm{f}_{\text {S'up }}$ would have to be 0.12 and $\mathrm{f}_{\text {pS'up }}=0.20$. Both these values are considerably different than those observed.

\section{Calculating the constants in the hydrolysis kinetic equations - Izzett et al. (1992) results}

Izzett et al. (1992) operated two laboratoryscale mesophilic $\left(37^{\circ} \mathrm{C}\right)$ anaerobic digesters fed a mixture of primary and humus (trickling filter) sludge from the Potsdam wastewater treatment plant (Milnerton, Cape, South Africa) at 7, 10, 12, 15 and 20 d retention time. The steady state experimental results measured on the systems are listed in Table 2.

Accepting $\mathrm{f}_{\mathrm{pS} \text {, }}=0.36$ from Sötemann et al. (2005a) for the Izzett data, the calculated $\mathrm{S}_{\mathrm{bp}}$ concentrations from Eq. 25 are listed in Table 3. With $S_{b p}$ known, $Z_{A D}$ and $\Delta S_{b p}$ $\left(=\mathrm{S}_{\mathrm{bpi}}-\mathrm{S}_{\mathrm{bp}}\right)$ can be calculated from the measured results (Table 3). Because the hydrolysis process does not reach completion in the digester, the observed hydrolysis rate $r_{h}$ is given by Eq. 12 and the calculated values are listed in Table 3. With the hydrolysis rate known, the kinetic constants in the various hydrolysis rate equations can be calculated, i.e. for the first order rate with respect to $\mathrm{S}_{\mathrm{bp}}$ only (Eq. 1), $K_{h}=r_{h} / S_{b p}(/ \mathrm{d})$ and for the first order specific rate with respect to $\mathrm{S}_{\mathrm{bp}}$ and $\mathrm{Z}_{\mathrm{AD}}$ (Eq. 2), $K_{H}=$ $r_{h} /\left(S_{b p} Z_{A D}\right)[\ell /(\mathrm{gCOD}$ biomass $\cdot \mathrm{d})]$

The calculated $\mathrm{K}_{\mathrm{h}}$ and $\mathrm{K}_{\mathrm{H}}$ rates for the different retention times are listed in Table 3 and plotted versus R in Fig. 4. For a hydrolysis rate equation to be reasonably general, it should take into account the major factors that influence the rate. If it achieves this, then the

\section{TABLE 3}

Izzett et al. (1992) 7 to $20 \mathrm{~d}$ retention time $(R)$ anaerobic digester measured influent ${ }^{*}\left(S_{t i}\right)$ and effluent ${ }^{*}\left(S_{t e}\right)$ COD concentrations, influent unbiodegradable $\left(S_{u p i}\right)$ and biodegradable COD $\left(S_{b p i}\right)$ concentrations for an unbiodegradable COD fraction ( $f_{P S^{\prime} \text { up }}$ ) of 0.36 , calculated residual biodegradable COD concentration $\left(S_{b p}\right)$ (Eq. 25), change in biodegradable concentration across digester $\left(\Delta S_{b p}\right)$, observed hydrolysis rate $\left(r_{h}=\Delta S_{b p} / R+b_{A D} Z_{A D}\right.$, Eq. 12), acidogen biomass concentration $\left(Z_{A D}\right)$, specific hydrolysis rate $\left.\left[r_{h} / Z_{A D}\right)\right]$ and the $1^{\text {st }}$ order and $1^{\text {st }}$ order specific hydrolysis rate constants $\left(K_{\text {and }}\right.$ an $\left.K_{H}\right)$. All mass units in gCOD.

\begin{tabular}{|c|c|c|c|c|c|c|c|c|c|c|c|}
\hline $\mathbf{R}$ & ${ }^{*} \mathbf{S}_{\mathrm{ti}}$ & ${ }^{*} \mathbf{S}_{\mathrm{te}}$ & $\mathbf{S}_{\mathrm{upi}}$ & $\mathbf{S}_{\mathrm{bpi}}$ & $\mathbf{S}_{\mathbf{b p}}$ & $\Delta \mathbf{S}_{\mathbf{b p}}$ & $\mathbf{r}_{\mathbf{h}}$ & $\mathbf{Z}_{\mathrm{AD}}$ & $\mathbf{r}_{\mathbf{h}} / \mathbf{Z}_{\mathrm{AD}}$ & $\mathbf{K}_{\mathrm{h}}$ & $\mathbf{K}_{\mathrm{H}}$ \\
\hline $\mathbf{d}$ & $\mathbf{g} / \ell$ & $\mathbf{g} / \ell$ & $\mathbf{g} / \ell$ & $\mathbf{g} / \ell$ & $\mathbf{g} / \ell$ & $\mathbf{g} / \ell$ & $\mathbf{g} /(\ell \cdot \mathbf{d})$ & $\mathbf{g} / \ell$ & $\begin{array}{c}\mathbf{g C O D} \mathbf{S}_{\mathbf{b p}} I \\
\left(\mathbf{g C O D} \mathbf{Z}_{\mathrm{AD}} \cdot \mathbf{d}\right)\end{array}$ & $\begin{array}{c}\ell / \mathbf{d} \\
\left(\mathbf{g C O D} \mathbf{Z}_{\mathrm{AD}} \cdot \mathbf{d}\right)\end{array}$ \\
\hline 7 & 43.286 & 23.637 & 15.583 & 25.832 & 6.240 & 19.59 & 2.871 & 1.765 & 1.586 & 0.460 & 0.261 \\
10 & 40.721 & 20.521 & 14.660 & 24.100 & 4.142 & 19.96 & 2.064 & 1.654 & 1.207 & 0.498 & 0.301 \\
12 & 39.222 & 18.678 & 14.120 & 22.230 & 3.018 & 19.21 & 1.663 & 1.511 & 1.059 & 0.551 & 0.365 \\
15 & 42.367 & 19.969 & 15.252 & 25.291 & 3.065 & 22.23 & 1.548 & 1.625 & 0.912 & 0.505 & 0.311 \\
20 & 42.595 & 19.005 & 15.334 & 25.012 & 2.151 & 22.86 & 1.204 & 1.495 & 0.764 & 0.560 & 0.374 \\
\hline & & & & & & & & & Mean** & 0.515 & 0.322 \\
\hline
\end{tabular}

* Measured total unfiltered COD. The VFA concentration was subtracted from this in conformity with Eq. 5 when calculating the $Z_{\text {aD }}$ because this concentration is already hydrolysed and produces negligible biomass in the digester. The unbiodegradable soluble COD concentration was assumed zero. The fermentable (non-VFA) soluble COD (Fig. 2) was included in the $\mathrm{S}_{\text {bi }}$ (in conformity with Eq. 5) because these organics pass through the hydrolysis process like the $\mathrm{S}_{\mathrm{bpi}}$. The unbiodegradable COD concentration $\left(\mathrm{S}_{\mathrm{upi}}\right)$ of the sludge was calculated from the influent total unfiltered COD as listed and therefore included the soluble COD. This was done to approximate the unbiodegradable COD concentration of the "pristine" sewage sludge before any acidogenesis commenced. This is approximate because hydrogen is generated and lost in the acidogenesis that takes place in the sludge before feeding to the digester.

** Mean of all five retention time values. 